\title{
Teachers' Perceived Knowledge and Confidence Regarding Adolescent Concussion Management
}

\author{
Margaret L. Ha ${ }^{1}$, Tricia M. Kasamatsu ${ }^{2}$, Tamara C. Valovich McLeod ${ }^{3}$, Johna K. Register-Mihalik ${ }^{4} \&$ Cailee E. \\ Welch Bacon ${ }^{3}$ \\ ${ }^{1}$ Sports Conditioning and Rehabilitation, Orange, California, United States \\ ${ }^{2}$ California State University Fullerton, Fullerton, California, United States \\ ${ }^{3}$ A.T. Still University, Mesa, Arizona, United States \\ ${ }^{4}$ University of North Carolina at Chapel Hill, Chapel Hill, North Carolina, United States \\ Correspondence: Tricia M. Kasamatsu, Department of Kinesiology and Athletic Training Program at California \\ State University, 800 N. State College Blvd., Fullerton, California 92831, United States. E-mail: \\ tkasamatsu@fullerton.edu
}

Received: June 25, 2020 Accepted: July 30, 2020 Online Published: August 17, 2020

doi:10.5539/jel.v9n5p27 URL: https://doi.org/10.5539/jel.v9n5p27

\begin{abstract}
Teachers play an important role in facilitating a student's return to school after a concussion. Currently, there is limited evidence on teachers' experiences and their role in managing concussions in the classroom. This study investigated teachers' perceived knowledge and confidence regarding concussion recognition and management. A cross-sectional design was used for this online survey of secondary school teachers in the United States. Practicing teachers self-reported being moderately knowledgeable and confident in their knowledge of concussion signs and symptoms. Whereas teachers were moderately knowledgeable and confident in their knowledge of academic support strategies after a student's concussion, teachers were minimally knowledgeable and confident in their knowledge of the criteria for the student's return to school and activity. Personal history of concussion and participation in formal concussion education were associated with increases in teachers' perceived knowledge and confidence regarding concussion and its management process. Overall, teachers believed it was important to learn about concussions to support a student's return to school. Therefore, integration of concussion education into preservice teacher education programs and in-service trainings is recommended. Providing teachers with practical resources on academic adjustments can enhance the support provided to symptomatic students, reduce misconceptions about concussion, and facilitate dialogue among stakeholders involved in the management of concussions.
\end{abstract}

Keywords: brain injury, professional development, return to learn, secondary school, teacher knowledge

\section{Introduction}

Because of their ability to recognize changes in a student's academic performance and behavior, teachers play a key role in a student's return to school following a concussion. Symptoms associated with concussion (i.e., physical, cognitive, emotional) can affect a student's learning, such as the ability to complete homework in a timely manner or retain/recall information. Challenges associated with concussion symptoms may also result in a prolonged recovery or a decline in the student's academic performance (Halstead et al., 2013; Prasad, Swank, \& Ewing-Cobbs, 2017; Treble-Barna et al., 2017). After a concussion, students in primary and secondary schools have reported difficulty with understanding new material and managing symptoms that interfere with productivity (Ransom et al., 2016). For example, double vision, sensitivity to light or sound, or difficulty concentrating can cause challenges with paying attention in class or completing assessments when the student returns to school (Swanson et al., 2017). Although no significant decreases in a student's grade point average immediately after a concussion have been observed, some students may experience long-term functional deficits that affect academic performance (Lowry et al., 2019; Russell, Selci, Chu, Rozbacher, \& Ellis, 2017; Wasserman, Bazarian, Mapstone, Block, \& van Wijngaarden, 2016). Therefore, targeted support is warranted during the student's recovery from concussion to prevent falling behind in coursework and declining academic performance. 
In 2018, the Centers for Disease Control and Prevention (Lumba-Brown et al., 2018) released guidelines for the management of mild traumatic brain injury (TBI), including concussion. Best practice recommendations include a gradual return to school and the inclusion of academic support strategies for symptomatic students (Lumba-Brown et al., 2018). These support strategies, or academic adjustments (AA), are chosen based on the student's symptoms and functional deficits and are intended to limit symptom exacerbation after the student's re-integration to the school environment and classroom (Halstead et al., 2013; McAvoy, Eagan-Johnson, \& Halstead, 2018). To promote whole person care, health care professionals are encouraged to recommend specific AA when the student returns to school after concussion (Lumba-Brown et al., 2018; Rieger, Lewandowski, Potts, \& Shea, 2019). Teachers are thereby tasked with integrating AA for a symptomatic student and noting improvements or declines throughout the student's recovery (McAvoy et al., 2018). These informal AA are similar to the support provided in an Individualized Education Program or Section 504 plan, but are ideally provided immediately after injury (1-4 weeks) and slowly eliminated as symptoms resolve (McAvoy et al., 2018). Although teachers play a critical role in implementing AA and monitoring academic performance as part of the concussion management process, little is known regarding their knowledge of concussions and preparation to assist a student throughout the recovery process.

\section{Literature Review}

\subsection{Teachers' Knowledge}

Studies of teachers' personal and professional knowledge have explored various educational topics, such as curriculum, instructional strategies, and professional development (Ben-Peretz, 2011; Birman, Desimone, Porter, \& Garet, 2000; Guskey, 1986). Personal knowledge refers to an individual's experiences and epistemology. Professional knowledge describes an individual's understanding of pedagogical tools, curricular design, and content knowledge of the subject taught (Grossman \& Richert, 1988). Pedagogical content knowledge, also referred to as subject matter knowledge, has been used to describe a teacher's understanding of how to organize and teach the content (Connelly, Clandinin, \& He, 1997). Pedagogical content knowledge evolves with teaching experience and ongoing consideration of student perceptions while learning the subject matter (Tamir, 1991). Together, this concept of personal practical knowledge represents the blending of knowledge, beliefs, and experiences that inform professional practice (Tamir, 1991).

In addition to developing pedagogical content knowledge, teacher education programs are also charged with determining how to best prepare teachers for changes within the landscape of education (Ben-Peretz, 2011). For example, teachers and students must critically assess information presented in the media (Holden \& Hicks, 2007), which may shape their knowledge and perceptions of topics (Ahmed \& Hall, 2017), such as concussion. Teachers' personal knowledge (understanding of and experiences with concussion), professional knowledge (preparation to adjust instructional strategies or accommodate student needs), and beliefs (perceptions of concussion and its relationship to learning) may play a role in the management of a student's return to school after concussion. Although medical professionals recommend AA as part of best practices for concussion management (Halstead et al., 2013; Lumba-Brown et al., 2018), it is unclear if teachers are knowledgeable about AA and prepared to implement it in their classrooms.

\subsection{Teachers' Knowledge of Brain Injury}

Investigation of the transition to school after brain injury is not new and has primarily focused on long-term strategies after TBI rather than short-term management of concussion. In a comparison of knowledge of TBI between educators and rehabilitation staff (e.g., nurses, physical therapists, occupational therapists, physician/resident), educators had more misconceptions about the student's experience after TBI and during the recovery process than rehabilitation staff (Farmer \& Johnson-Gerard, 1997). Educators have also inaccurately reported the belief that a previous mild TBI would not affect a student's current academic performance (Hawley, Ward, Magnay, \& Mychalkiw, 2004) and that academic ability afterward was primarily related to effort (Linden, Braiden, \& Miller, 2013). However, increases in educators' knowledge and confidence about TBI diagnosis and management have been associated with previous experience working with a child with TBI (Farmer \& Johnson-Gerard, 1997; Linden et al., 2013) or completion of training in special education (Ettel, Glang, Todis, \& Davies, 2016). Therefore, a proactive approach of providing all educators with strategies to facilitate the transition to school and to address the individualized needs of students after TBI is recommended (Bowen, 2005; Linden et al., 2013; Lumba-Brown et al., 2018).

When specifically considering concussion, teachers in primary and secondary schools reported being somewhat confident and fairly knowledgeable at recognizing common concussion symptoms (e.g., headaches, trouble concentrating), but were less familiar with emotional symptoms (e.g., depression, mood changes) and behavioral 
changes (e.g., impulsivity) associated with concussion (Dreer, Crowley, Cash, O'Neill, \& Cox, 2016). Teachers, coaches, and school administrators also indicated misconceptions about activities that may exacerbate symptoms and were unable to identify specific AA for select concussion symptoms (Carzoo, Young, Pommering, \& Cuff, 2015). Teachers with a personal history of concussion had a better understanding of how a concussion can affect learning (Romm et al., 2016), but teachers have also reported discomfort about translating broad recommendations to specific interventions within their classrooms (Graff \& Caperell, 2016; Lyons et al., 2017). Although strategies to diversify instruction are taught in teacher education programs, practicing teachers have reported the desire for additional resources on AA and its practical applications for students recovering from concussion (Dreer et al., 2016; Sarmiento, Donnell, Bell, \& Hoffman, 2019).

\subsection{Theory of Planned Behavior}

Because teachers have daily interactions with students and an active role in implementing AA in the classroom, we believed it was important to understand their knowledge and confidence regarding concussions. This investigation was framed within the theory of planned behavior to explore how teachers' perceived knowledge and beliefs about concussion may affect their teaching practices. To understand human behavior, Ajzen (1991) theorized an individual's attitudes, perceived ability, intentions, and perceptions of society's belief about a concept or behavior influence the decision to act or not act. The theory of planned behavior has been used in education when exploring in-service teachers' instructional practices (Haney \& McArthur, 2002), in health care when investigating athletic trainers' concussion management practices (Rigby, Vela, \& Housman, 2013), and with student-athletes' concussion reporting behaviors (Kroshus, Kubzansky, Goldman, \& Austin, 2014). As such, it is likely teachers' perceived knowledge and beliefs about concussion may influence their interactions with a symptomatic student or the decision to implement AA during a student's return to school process after concussion. Although it was beyond the scope of the investigation to directly test this theory, better understanding of teachers' perceived knowledge of concussion may facilitate dialogue on AA and enhance the support provided to students on their return to school.

\subsection{Research Questions}

The purpose of this study was to examine teachers' perceived knowledge and confidence regarding concussion recognition and management. The research questions included the following: (1) What are teachers' self-reported knowledge and confidence regarding adolescent concussion management? (2) Are teachers' self-reported knowledge and confidence of adolescent concussion management associated with participation in formal concussion education? or (3) Are they associated with prior personal history of concussion? We hypothesized completion of formal concussion education and prior personal history of concussion would be associated with increases in teachers' perceived knowledge and confidence regarding concussion and its management process.

\section{Methods}

\subsection{Survey Instrument}

A previously validated instrument (Williams, Welch Bacon, Parsons, \& Valovich McLeod, 2015), the Beliefs, Attitudes \& Knowledge of Pediatric Adolescent Concussion (BAKPAC), was modified (BAKPAC-TEACH) to specifically target teachers. The BAKPAC-TEACH was piloted by three teachers for content and readability. Four items were revised for clarity based on pilot feedback. The final BAKPAC-TEACH survey included the following sections: (1) perceived knowledge and confidence about concussion, (2) secondary school teacher collaboration, (3) established relationships with health care providers, and (4) perceptions of academic adjustments. This article only presents teachers' knowledge and confidence regarding adolescent concussion. The perceived knowledge and confidence section contained 10, multi-part, closed-ended items. There were a variety of multiple choice, multiple answer, and 4-point Likert scale items regarding their perceptions of importance $(1=$ not important at all, $4=$ extremely important $)$, self-reported knowledge $(1=$ not knowledgeable at all, $4=$ extremely knowledgeable), and self-reported confidence $(1=$ not confident at all, $4=$ extremely confident) about concussion.

\subsection{Data Collection}

Institutional review board approval was obtained before the study. An e-mail was sent to a random selection of secondary school teachers across the United States. The e-mail explained the purpose of the study, estimation of the time to complete the survey, contact information of the researchers, and a hyperlink to the online survey. The survey was open for 4 weeks, and a reminder e-mail was sent at the 2-week time point. Consent was implied if the teacher started the survey, and all responses were anonymous. Responses to individual survey items were not 
required; therefore, questions could be skipped if they preferred not to respond.

\subsection{Data Analysis}

Descriptive statistics (frequencies, means, and standard deviations) were calculated for teacher demographics and individual survey items. Because teachers could skip questions, total responses for each item are presented. Composite scores for knowledge and confidence were calculated by totaling the values of 7 Likert-type questions and averaging those scores back to the original 4-point scale $(1=$ not knowledgeable/confident at all, 4 = extremely knowledgeable/confident). Mann Whitney tests were used to assess group differences (i.e., completion of formalized concussion education, prior personal history of concussion) for knowledge and confidence composites and individual Likert-type items. All analyses were performed using SPSS version 26 (IBM Corporation, Armonk, NY) software with a pre-determined $\alpha$ level set at $p<.05$.

\section{Results}

\subsection{Demographics of Participants}

Of the 5877 teachers recruited for this study, 426 teachers across 45 states accessed the survey (survey access rate $=7.2 \%$ ). A total of 349 completed surveys were analyzed (survey completion rate $=81.9 \%$ ). Of those, $35.8 \%$ (125) of respondents were men and 55.6\% (194) women; 30 responses for sex were missing. Teachers' average age was $44.9 \pm 12.0$ years. Additionally, they reported $15.5 \pm 10.8$ years of teaching experience and were primarily employed in the high school setting (90.0\%). Additional school and teacher characteristics are presented in Table 1.

Table 1. Additional school and participant demographics

\begin{tabular}{|c|c|c|}
\hline Variable & No. & $\%^{\mathrm{a}}$ \\
\hline \multicolumn{3}{|l|}{ Location of school } \\
\hline Urban & 59 & 16.9 \\
\hline Suburban & 152 & 43.6 \\
\hline Rural & 108 & 30.9 \\
\hline Other & 2 & 0.5 \\
\hline Missing & 28 & 8.0 \\
\hline \multicolumn{3}{|l|}{ Student enrollment } \\
\hline$<250$ & 25 & 7.2 \\
\hline $250-499$ & 39 & 11.2 \\
\hline $500-999$ & 70 & 20.1 \\
\hline $1000-1999$ & 119 & 34.1 \\
\hline $2000-2999$ & 56 & 16.0 \\
\hline $3000-3999$ & 9 & 2.6 \\
\hline 4000-4999 & 3 & 0.9 \\
\hline Missing & 28 & 8.0 \\
\hline \multicolumn{3}{|l|}{ Highest level of education } \\
\hline Bachelors & 113 & 32.4 \\
\hline Masters & 198 & 56.7 \\
\hline Doctorate & 9 & 2.6 \\
\hline Clinical doctorate & 1 & 0.3 \\
\hline Missing & 28 & 8.0 \\
\hline \multicolumn{3}{|l|}{ Current level of teaching } \\
\hline Preschool & 1 & 0.3 \\
\hline Elementary & 5 & 1.4 \\
\hline Middle & 11 & 3.2 \\
\hline Junior high & 13 & 3.7 \\
\hline High school & 314 & 90.0 \\
\hline Not currently teaching & 1 & 0.3 \\
\hline Other & 1 & 0.3 \\
\hline Missing & 3 & 0.9 \\
\hline \multicolumn{3}{|l|}{ Subjects taught } \\
\hline Art & 9 & 2.6 \\
\hline Career technical education & 14 & 4.0 \\
\hline English & 45 & 12.9 \\
\hline Foreign language & 27 & 7.7 \\
\hline History \& social sciences & 47 & 13.5 \\
\hline Math & 32 & 9.2 \\
\hline Science & 73 & 20.9 \\
\hline Technology \& computer science & 8 & 2.3 \\
\hline Other & 33 & 9.5 \\
\hline I currently do not teach & 1 & 0.3 \\
\hline Missing & 60 & 17.2 \\
\hline
\end{tabular}

Note. ${ }^{a}$ Percentages were rounded; therefore, the sum may not equal $100 \%$. 


\subsection{General Concussion Knowledge}

Most teachers accurately identified that a concussion is an injury to the brain $(94.6 \%, 330 / 349)$, while few inaccurately reported it is an injury to the skull $(5.2 \%, 18 / 349)$ or neck $(0.3 \%, 1 / 349)$. Teachers commonly identified headache $(86.8 \%, 303 / 349)$ and confusion $(82.8 \%, 289 / 349)$ as primary signs and symptoms, but less often considered fatigue/low energy $(44.1 \%, 148 / 349)$, irritability $(39.3 \%, 137 / 349)$, being more emotional $(30.4 \%, 106 / 349)$, nervous/anxiousness $(26.1 \%, 91 / 349)$, and trouble falling asleep $(24.4 \%, 85 / 349)$ as primary symptoms associated with concussions. Teachers' responses regarding consequences associated with returning to play too soon after concussion or sustaining multiple concussions over time are presented in Table 2 .

Table 2. Teachers' perceptions of consequences related to concussion

\begin{tabular}{lll}
\hline Consequence & No. & $\%^{\mathrm{a}}$ \\
\hline Returning to play too soon & & \\
$\quad$ Brain damage & 318 & 91.1 \\
More likely to get another concussion & 276 & 79.1 \\
Trouble in school & 243 & 69.6 \\
Emotional problems & 218 & 62.5 \\
Changes in social life & 167 & 47.9 \\
Skin rash & 4 & 1.1 \\
I don't know what might happen & 3 & 0.9 \\
No bad things & 1 & 0.3 \\
Sustaining multiple concussions & & \\
Brain damage & 344 & 98.6 \\
More likely to get another concussion & 236 & 67.6 \\
Trouble in school & 286 & 81.9 \\
Emotional problems & 300 & 86.0 \\
Changes in social life & 260 & 74.5 \\
Skin rash & 8 & 2.3 \\
I don't know what might happen & 3 & 0.9 \\
No bad things & 1 & 0.3 \\
\hline
\end{tabular}

Note. ${ }^{\text {a }}$ Participants were able to select more than one option; therefore, the sum may not equal $100 \%$.

\subsection{Prior Concussion Education}

The majority of teachers $(68.9 \%, 126 / 183)$ reported formal concussion education was not mandated in their state of employment. Further, 43.1\% (138/320) indicated they had participated in formal concussion education, and $56.9 \%(182 / 320)$ had never participated in formal concussion education. Participation in formal concussion education was associated with increases in composite scores for teachers' perceived knowledge $(p<.001)$ and confidence in their knowledge of concussion $(p<.001)$. Teachers formally educated about concussions reported being moderately knowledgeable $(M=3.1 / 4.0 \pm 0.44)$ and moderately confident in their knowledge $(M=3.1 / 4.0$ $\pm 0.50)$, whereas teachers without concussion education reported being minimally knowledgeable $(M=2.2 / 4.0 \pm$ $0.57)$ and minimally confident $(M=2.1 / 4.0 \pm 0.62)$ in their knowledge of concussion and its management process. Differences between individual items within the composite scores are presented in Figure 1. 


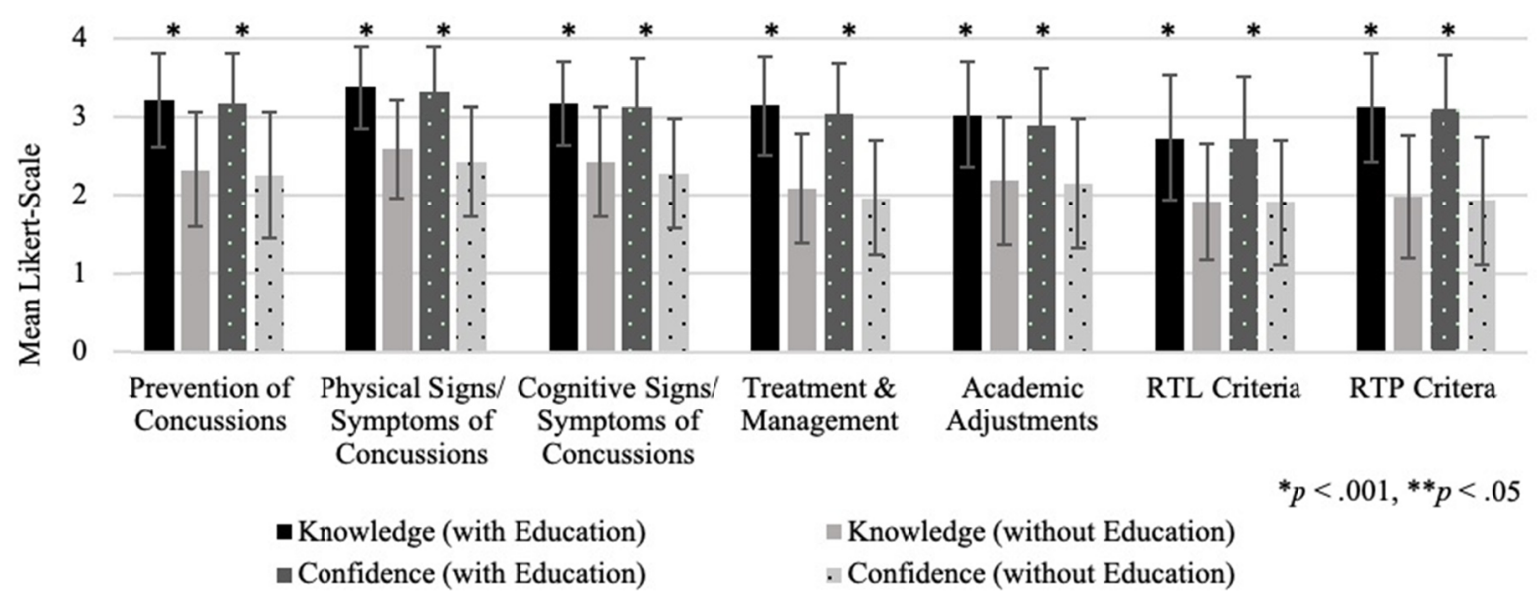

Figure 1. Comparison of knowledge and confidence composite items for teachers with and without concussion education

Note. Abbreviations: RTL, return to learn; RTP, return to play.

Both groups of teachers reported it was extremely important to know the steps to follow when an adolescent had a concussion $(M=3.78 / 4.0 \pm 0.50, p=.30)$. Those with formalized concussion education reported it was extremely important to limit cognitive activities after a concussion $(M=3.6 / 4.0 \pm 0.59, p<.001)$ and for teachers to learn how a concussion can be prevented $(M=3.4 / 4.0 \pm 0.76, p=0.16)$. Conversely, teachers without formal education stated it was moderately important to limit cognitive activities $(M=3.3 / 4 \pm 0.76)$ and for teachers to know how a concussion can be prevented $(M=3.3 / 4.0 \pm 0.82)$.

\subsection{Prior Personal Concussion History}

Of the teachers who responded, $34.3 \%$ (109/318) had personally sustained a concussion. Personal prior history of concussion was associated with increases in composite scores for teachers' perceived knowledge $(p<.001)$ and confidence in their knowledge $(p<.001)$ of concussion. Teachers with a prior personal history of concussion reported being moderately knowledgeable $(M=2.9 / 4.0 \pm 0.64)$ and moderately confident in their knowledge $(M$ $=2.8 / 4.0 \pm 0.68)$ of concussion. Conversely, teachers who had not personally sustained a concussion reported being minimally knowledgeable $(M=2.5 / 4.0 \pm 0.66)$ and minimally confident in their knowledge $(M=2.36 / 4.0$ \pm 0.72 ) of concussion. Figure 2 presents a comparison of teachers' responses for individual items within the composite scores.

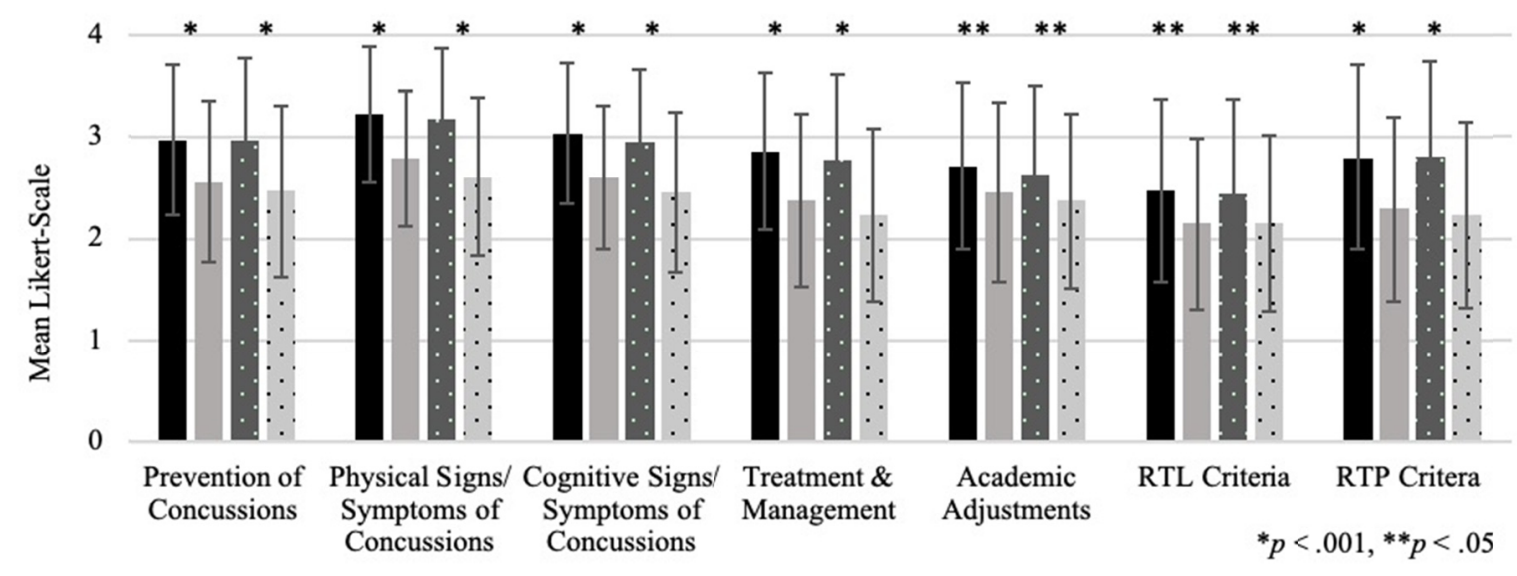

-Knowledge (with Personal History)

Confidence (with Personal History) $\square$ Knowledge (without Personal History)
$\square$ Confidence (without Personal History)

Figure 2. Comparison of knowledge and confidence composite items for teachers with and without personal history of concussion

Note. Abbreviations: RTL, return to learn; RTP, return to play. 
Both groups of teachers believed it was extremely important to know how a concussion occurs $(M=3.6 / 4.0 \pm$ $0.63, p=.19)$ and the steps to follow once a student has a concussion $(M=3.8 / 4.0 \pm 0.50, p=.93)$. Both groups also believed it was extremely important for students to limit cognitive activity following a concussion $(M=$ $3.4 / 4.0 \pm 0.71, p=.41)$ and for teachers to know how a concussion can be prevented $(M=3.3 / 4.0 \pm 0.74, p$ $=.67)$.

\section{Discussion}

\subsection{Perceptions of General Concussion Knowledge}

Similar to Dreer et al. (2016), the teachers in the current investigation successfully identified commonly associated physical (i.e., headache, blurred vision) and cognitive (i.e., confusion, difficulty remembering and concentrating) signs and symptoms of concussion, but were less likely to identify emotional or behavioral symptoms as primary indicators of concussion. Changes in sleep patterns and mood may occur with concussion and could be mistaken for poor behavior instead of exacerbated concussion symptoms (Broshek, De Marco, \& Freeman, 2015; Farmer \& Johnson-Gerard, 1997; Mainwaring, Hutchison, Camper, \& Richards, 2012). Although teachers are not expected to allow inappropriate behavior or classroom disruptions caused by concussion symptoms, recognizing when concussion symptoms return can be useful to avoid future triggers and implement AA when needed. For example, taking notes in class can be problematic for a student who has difficulty visually tracking between the desktop and the front of the class. This may result in a headache, dizziness, or distracted behaviors that can be prevented with access to the teacher's notes or a temporarily assigned note taker. In another scenario, a student experiencing difficulty with organizational skills or working memory may benefit from using a planner or following written instructions when completing an assignment (Halstead et al., 2013). The intent of AA is to limit symptom recurrence, but it can also decrease a student's anxiety over missed schoolwork during the recovery process (Ransom et al., 2016; Rieger et al., 2019).

Currently, experts recommend the use of a school-based concussion team that includes health care and school professionals (Lumba-Brown et al., 2018). This collaboration builds on each member's expertise and can address the gap between understanding a student's health-related needs while balancing academic demands. Health care professionals can conduct periodic clinical exams to identify appropriate AA and limit a student's attempts to unnecessarily extend the use of AA to avoid schoolwork. Furthermore, teachers have indicated that specific return to school guidelines from health care professionals are helpful since it is taxing to identify AA to implement while also accommodating students with other special needs in the same classroom or across class periods (Romm et al., 2018). Although some schools may require a formal concussion diagnosis or physician's note to initiate AA (Blackwell, Robinson, Proctor, \& Taylor, 2017), principals in Ohio approved of teachers initiating AA (e.g., decreased homework load, extending time on assessments, rest breaks) at their discretion (Heyer, Weber, Rose, Perkins, \& Schmittauer, 2015). Therefore, school professionals should discuss the role of the concussion team in the absence of specific physician recommendations, and teachers should be empowered to make content-related or classroom environment adjustments as needed (Halstead et al., 2013).

\subsection{Concussion Education}

Formal concussion education was associated with increases in teachers' perceived knowledge and confidence regarding adolescent concussion management. Interestingly, teachers in our study who completed concussion education also believed it was more important to limit cognitive activities after concussion and perceived themselves as more knowledgeable and confident about AA than teachers without concussion education. Carzoo et al. (2015) did not observe this association; however, these researchers specifically assessed teachers' knowledge of AA, and it is plausible AA may not have been included in concussion education at the time of their study. Although AA are similar to teachers training on accommodations, previous reports have indicated teachers want additional training on AA and access to resources about AA implementation for concussion specifically (Dreer et al., 2016; Lyons et al., 2017). Targeted concussion education in schools has been associated with more academic support for students after concussion (Davies, Sandlund, \& Lopez, 2016; Romm et al., 2018), improvements in knowledge of concussion by school professionals and the use of a team approach to managing concussions in schools (Glang et al., 2015). School-based concussion resources already exist (e.g., BrainSTEPS; Brain101; Reduce, Educate, Adjust, Pace) and are accessible online for school professionals seeking to develop a concussion team and procedures for supporting a student after concussion.

To prepare teachers and school professionals to manage concussions in an effective and timely manner, in-service and preservice training on concussion is recommended (Lumba-Brown et al., 2018; Lyons et al., 2017). For preservice teachers, an educational workshop with other health care or school-related professional programs could disseminate pertinent concussion information and prepare teachers for interprofessional practice. For 
practicing teachers, an in-service program can be developed with the assistance of a teacher, school nurse, or athletic trainer who is already familiar with concussion management and return to school resources. These workshops should utilize case studies so teachers can practice integrating AA based on the student's symptoms and physician's recommendations, while also making necessary adjustments within the context of their teaching assignments (e.g., environmental adjustments for science laboratory activities or art class, adjustments in participation during physical education). Another professional development activity could involve school personnel discussing these strategies within professional learning communities to allow for ongoing feedback, assistance, and mentorship. This interactive and ongoing approach to professional development (Guskey, 1986; Hachem, Kourtis, Mylabathula, \& Tator, 2016; Huston \& Weaver, 2008; Lumpe, 2007) may be more relevant and effective than a short lecture on concussion alone.

\subsection{Personal History of Concussion}

Teachers in our study with a personal history of concussion perceived themselves to be more knowledgeable and confident in their knowledge than teachers without this experience. Romm et al. (2018) found teachers with a prior history of concussion were more sympathetic toward a student's needs after concussion. A teacher who is familiar with concussion symptoms may better understand how a concussion can affect the student's ability to stay engaged in class, complete homework across all courses, and recall information. Additionally, personal history of concussion may help teachers relate to the student's challenges after returning to school, particularly since concussion lacks visible injury markers, such as a cast or noticeable bruising. Although we did not objectively measure teachers' actual knowledge and confidence, based on the theory of planned behavior, their perceived knowledge and beliefs may influence their classroom practices and level of support given to students after a concussion. Emphasizing the student's experience after concussion and the teacher's experiences during concussion trainings may be an effective strategy to establish relevance and encourage implementation of AA (Birman et al., 2000).

\subsection{Limitations}

Our study response rate of $7 \%$ was lower than desired but is consistent with average response rates for online surveys when initial contact with a specific group is made by e-mail (Sinclair, O'Toole, Malawaraarachchi, \& Leder, 2012). Additionally, the demographic characteristics of our sample of teachers was similar to reports of teacher demographics in the United States (Feistritzer, Griffin, \& Linnajarvi, 2011). As such, our demographics can be referred to when interpreting the results for a specific school environment. Another possible limitation is that people who were interested in concussions were more likely to complete our survey, so our results may not adequately represent the perspectives of all teachers. However, we believed it was important to report these findings to generate a dialogue on concussion and its potential impact on the academic performance and return to daily function of students after a concussion. In this study, we asked our participants for their perceived knowledge and confidence ratings; therefore, we were unable to examine actual differences in knowledge between the different groups. However, perceived knowledge and confidence can still inform teachers' intentions of implementing AA in their classrooms and aid in understanding their role in this process. As with any survey investigation, we also relied on participants' honesty. Anonymous reporting and the ability to skip questions were utilized to encourage honest responses from teachers.

\subsection{Future Directions}

Currently a return to school protocol with AA is recommended; however, there is limited evidence on teachers' experiences and role in managing concussions in the classroom. Future researchers should explore teachers' experiences when implementing AA or the challenges that occur when supporting a student throughout the concussion recovery process. Ongoing research on effective professional development formats (e.g., workshop series, peer mentoring, professional learning communities) for concussion education is needed to ensure that knowledge translates to implementation of AA in the classroom. Researchers could also investigate students' perceptions of the effectiveness of AA and their experiences returning to school following a concussion. These findings will help establish best practices for teachers implementing AA and for the overall management of concussions in schools.

\section{Conclusion}

Teachers play an important role in facilitating a student's return to school following a concussion. Teachers with a personal prior history of concussion and participation in formal concussion education reported being more knowledgeable and confident in their knowledge of concussions. However, all teachers believed it was important to learn about concussions and how they may affect a student's ability to attend class, complete homework, and recover fully. Particularly, the teachers in the current investigation believed it was important to learn the steps to 
follow once a student has a concussion and to understand how a concussion occurs. Therefore, we recommend the integration of concussion education into preservice teacher education programs and in-service faculty trainings. Providing practical resources for teachers on AA can enhance the support provided to symptomatic students, reduce misconceptions about brain injury, and facilitate dialogue among stakeholders involved in the management of concussions.

\section{Acknowledgments}

This work was supported by the A.T. Still University Strategic Research Fund, Mesa, Arizona (SRF_501-426).

\section{References}

Ahmed, O. H., \& Hall, E. E. (2017). "It was only a mild concussion": Exploring the description of sports concussion in online news articles. Physical Therapy in Sport, 23, 7-13. https://doi.org/10.1016/j.ptsp.2016.07.003

Ajzen, I. (1991). The theory of planned behavior. Organizational Behavior and Human Decision Processes, 50(2), 179-211. https://doi.org/10.1016/0749-5978(91)90020-T

Ben-Peretz, M. (2011). Teacher knowledge: What is it? How do we uncover it? What are its implications for schooling? Teaching and Teacher Education, 27(1), 3-9. https://doi.org/10.1016/j.tate.2010.07.015

Birman, B. F., Desimone, L., Porter, A. C., \& Garet, M. S. (2000). Designing professional development that works. Educational Leadership, 57(8), 28-33.

Blackwell, L. S., Robinson, A. F., Proctor, M. R., \& Taylor, A. M. (2017). Same care, different populations: Return-to-learn practices following concussion in primary and secondary schools. Journal of Child Neurology, 32(3), 327-333. https://doi.org/10.1177/088307381668135

Bowen, J. M. (2005). Classroom interventions for students with traumatic brain injuries. Preventing School Failure: Alternative Education for Children and Youth, 49(4), 34-41. https://doi.org/10.3200/PSFL.49.4.34-41

Broshek, D. K., De Marco, A. P., \& Freeman, J. R. (2015). A review of post-concussion syndrome and psychological factors associated with concussion. Brain Injury, 29(2), 228-237. https://doi.org/10.3109/02699052.2014.974674

Carzoo, S. A., Young, J. A., Pommering, T. L., \& Cuff, S. C. (2015). An evaluation of secondary school educators' knowledge of academic concussion management before and after a didactic presentation. Athletic Training and Sports Health Care, 7(4), 144-149. https://doi.org/10.3928/19425864-20150707-04

Connelly, F. M., Clandinin, D. J., \& He, M. F. (1997). Teachers' personal practical knowledge on the professional knowledge landscape. Teaching and Teacher Education, 13(7), 665-674. https://doi.org/10.1016/S0742-051X(97)00014-0

Davies, S. C., Sandlund, J. M., \& Lopez, L. B. (2016). School-based consultation to improve concussion recognition and response. Journal of Educational and Psychological Consultation, 26(1), 49-62. https://doi.org/10.1080/10474412.2014.963225

Dreer, L. E., Crowley, M. T., Cash, A., O’Neill, J. A., \& Cox, M. K. (2016). Examination of teacher knowledge, dissemination preferences, and classroom management of student concussions implications for return-to-learn protocols. Health Promotion Practice, 1-9. https://doi.org/1524839916650865

Ettel, D., Glang, A. E., Todis, B., \& Davies, S. C. (2016). Traumatic brain injury: Persistent misconceptions and knowledge gaps among educators. Exceptionality Education International, 26(1), 1-18.

Farmer, J. E., \& Johnson-Gerard, M. (1997). Misconceptions about traumatic brain injury among educators and rehabilitation staff: A comparative study. Rehabilitation Psychology, 42(4), 273. https://doi.org/10.1037/0090-5550.42.4.273

Feistritzer, C. E., Griffin, S., \& Linnajarvi, A. (2011). Profile of teachers in the US, 2011. Washington, DC: National Center for Education Information.

Glang, A. E., Koester, M. C., Chesnutt, J. C., Gioia, G. A., McAvoy, K., Marshall, S., \& Gau, J. M. (2015). The effectiveness of a web-based resource in improving postconcussion management in high schools. Journal of Adolescent Health, 56(1), 91-97. https://doi.org/10.1016/j.jadohealth.2014.08.011

Graff, D. M., \& Caperell, K. S. (2016). Concussion management in the classroom. Journal of Child Neurology, 31(14), 1569-1574. https://doi.org/10.1177/0883073816666205 
Grossman, P. L., \& Richert, A. E. (1988). Unacknowledged knowledge growth: A re-examination of the effects of teacher education. Teaching and Teacher Education, 4(1), 53-62. https://doi.org/10.1016/0742-051X(88)90024-8

Guskey, T. R. (1986). Staff development and the process of teacher change. Educational Researcher, 15(5), 5-12. https://doi.org/10.3102/0013189X015005005

Hachem, L. D., Kourtis, G., Mylabathula, S., \& Tator, C. H. (2016). Experience with Canada's first policy on concussion education and management in schools. Canadian Journal of Neurological Sciences, 43(4), 554-560. https://doi.org/10.1017/cjn.2016.41

Halstead, M. E., McAvoy, K., Devore, C. D., Carl, R., Lee, M., Logan, K., ... Koutures, C. G. (2013). Returning to learning following a concussion. Pediatrics, 132(5), 948-957. https://doi.org/10.1542/peds.2013-2867

Haney, J. J., \& McArthur, J. (2002). Four case studies of prospective science teachers' beliefs concerning constructivist teaching practices. Science Education, 86(6), 783-802. https://doi.org/10.1002/sce.10038

Hawley, C., Ward, A. B., Magnay, A. R., \& Mychalkiw, W. (2004). Return to school after brain injury. Archives of Disease in Childhood, 89(2), 136-142. https://doi.org/10.1136/adc.2002.025577

Heyer, G. L., Weber, K. D., Rose, S. C., Perkins, S. Q., \& Schmittauer, C. E. (2015). High school principals' resources, knowledge, and practices regarding the returning student with concussion. Journal of Pediatrics, 166(3), 594-599. https://doi.org/10.1016/j.jpeds.2014.09.038

Holden, C., \& Hicks, D. (2007). Making global connections: The knowledge, understanding and motivation of trainee teachers. Teaching and Teacher Education, 23(1), 13-23. https://doi.org/10.1016/j.tate.2006.04.031

Huston, T., \& Weaver, C. L. (2008). Peer coaching: Professional development for experienced faculty. Innovative Higher Education, 33(1), 5-20. https://doi.org/10.1007/s10755-007-9061-9

Kroshus, E., Kubzansky, L. D., Goldman, R. E., \& Austin, S. B. (2014). Norms, athletic identity, and concussion symptom under-reporting among male collegiate ice hockey players: A prospective cohort study. Annals of Behavioral Medicine, 49(1), 95-103. https://doi.org/10.1007/s12160-014-9636-5

Linden, M. A., Braiden, H. J., \& Miller, S. (2013). Educational professionals' understanding of childhood traumatic brain injury. Brain Injury, 27(1), 92-102. https://doi.org/10.3109/02699052.2012.722262

Lowry, R., Haarbauer-Krupa, J. K., Breiding, M. J., Thigpen, S., Rasberry, C. N., \& Lee, S. M. (2019). Concussion and academic impairment among US high school students. American Journal of Preventive Medicine, 57(6), 733-740. https://doi.org/10.1016/j.amepre.2019.08.016

Lumba-Brown, A., Yeates, K. O., Sarmiento, K., Breiding, M. J., Haegerich, T. M., Gioia, G. A., ... Timmons, S. D. (2018). Centers for Disease Control and Prevention guideline on the diagnosis and management of mild traumatic brain injury among children. JAMA Pediatrics, 172(11), e182853. https://doi.org/10.1001/jamapediatrics.2018.2853

Lumpe, A. T. (2007). Research-based professional development: Teachers engaged in professional learning

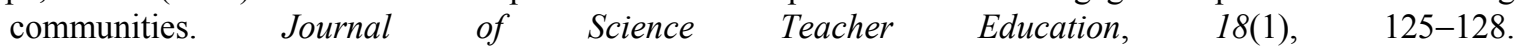
https://doi.org/10.1007/s10972-006-9018-3

Lyons, V. H., Moore, M., Guiney, R., Ayyagari, R. C., Thompson, L., Rivara, F. P., ... Vavilala, M. S. (2017). Strategies to address unmet needs and facilitate return to learn guideline adoption following concussion. Journal of School Health, 87(6), 416-426. https://doi.org/10.1111/josh.12510

Mainwaring, L., Hutchison, M., Camper, P., \& Richards, D. (2012). Examining emotional sequelae of sport concussion. Journal of Clinical Sport Psychology, 6(3), 247-274. https://doi.org/10.1123/jcsp.6.3.247

McAvoy, K., Eagan-Johnson, B., \& Halstead, M. (2018). Return to learn: Transitioning to school and through ascending levels of academic support for students following a concussion. NeuroRehabilitation, 42(3), 325-330. https://doi.org/10.3233/NRE-172381

Prasad, M. R., Swank, P. R., \& Ewing-Cobbs, L. (2017). Long-term school outcomes of children and adolescents with traumatic brain injury. Journal of Head Trauma Rehabilitation, 32(1), E24-E32. https://doi.org/10.1097/HTR.0000000000000218

Ransom, D. M., Burns, A. R., Youngstrom, E. A., Vaughan, C. G., Sady, M. D., \& Gioia, G. A. (2016). Applying an evidence-based assessment model to identify students at risk for perceived academic problems following concussion. Journal of the International Neuropsychological Society, 22(10), 1038-1049. 
https://doi.org/10.1017/S1355617716000916

Rieger, B., Lewandowski, L., Potts, H., \& Shea, N. (2019). Effects of concussion in adolescent students: Perceptions and performance. Journal of the International Neuropsychological Society, 25(8), 777-786. https://doi.org/10.1017/S13556177190004168

Rigby, J., Vela, L., \& Housman, J. (2013). Understanding athletic trainers' beliefs toward a multifacted sport-related concussion approach: Application of the theory of planned behavior. Journal of Athletic Training, 48(5), 636-644. https://doi.org/10.4085/1062-6050-48.3.10

Romm, K., Ferry, M., Caswell, A., Parham, C., Ambegaonkar, J., Cortes, N., \& Caswell, S. (2016). Public school teachers' and administrators' understanding of concussion management in the classroom. Journal of Athletic Training, 51(Suppl 6), 223-224.

Romm, K. E., Ambegaonkar, J. P., Caswell, A. M., Parham, C., Cortes, N. E., Kerr, Z., ... Caswell, S. V. (2018). Schoolteachers' and administrators' perceptions of concussion management and implementation of return-to-learn guideline. Journal of School Health, 88(11), 813-820. https://doi.org/10.1111/josh.12687

Russell, K., Selci, E., Chu, S., Rozbacher, A., \& Ellis, M. (2017). Academic outcomes and accommodations following adolescent sport-related concussion: A pilot study. Concussion, 2(4), CNC51. https://doi.org/10.2217/cnc-2017-0009

Sarmiento, K., Donnell, Z., Bell, E., \& Hoffman, R. (2019). From the CDC: A qualitative study of middle and high school professionals' experiences and views on concussion: Identifying opportunities to support the return to school process. Journal of Safety Research, 68, 223-229. https://doi.org/10.1016/j.jsr.2018.10.010

Sinclair, M., O'Toole, J., Malawaraarachchi, M., \& Leder, K. (2012). Comparison of response rates and cost-effectiveness for a community-based survey: Postal, internet and telephone modes with generic or personalised recruitment approaches. BMC Medical Research Methodology, 12(1), 132. https://doi.org/10.1186/1471-2288-12-132

Swanson, M. W., Weise, K. K., Dreer, L. E., Johnston, J., Davis, R. D., Ferguson, D., ... Busettini, C. (2017). Academic difficulty and vision symptoms in children with concussion. Optometry \& Vision Science, 94(1), 60-67. https://doi.org 10.1097/OPX.0000000000000977

Tamir, P. (1991). Professional and personal knowledge of teachers and teacher educators. Teaching and Teacher Education, 7(3), 263-268. https://doi.org/10.1016/0742-051X(91)90033-L

Treble-Barna, A., Schultz, H., Minich, N., Taylor, H. G., Yeates, K. O., Stancin, T., \& Wade, S. L. (2017). Long-term classroom functioning and its association with neuropsychological and academic performance following traumatic brain injury during early childhood. Neuropsychology, 31(5), 486-498. https://doi.org/10.1037/neu0000325

Wasserman, E. B., Bazarian, J. J., Mapstone, M., Block, R., \& van Wijngaarden, E. (2016). Academic dysfunction after a concussion among US high school and college students. American Journal of Public Health, 106(7), 1247-1253. https://doi.org/10.2105/AJPH.2016.303154

Williams, R. M., Welch Bacon, C. E., Parsons, J. T., \& Valovich McLeod, T. C. (2015). Athletic trainers' familiarity with and perceptions of academic accommodations in secondary school athletes after sport-related concussion. Journal of Athletic Training, 50(3), 262-269. https://doi.org/10.4085/1062-6050-49.3.81

\section{Copyrights}

Copyright for this article is retained by the author, with first publication rights granted to the journal.

This is an open-access article distributed under the terms and conditions of the Creative Commons Attribution license (http://creativecommons.org/licenses/by/4.0/). 